\title{
Crossing Thresholds with a Child with a Disability
}

\begin{abstract}
This essay takes up the concept of "thresholds" as it was developed in the Spring 2014 issue of Departures in Critical Qualitative Research. It opens up a fertile seam of thought about encounters with people labeled as "disabled" and with one's own child in particular. The article troubles the processes of normalization, and opens up the space of difference by excavating its unspeakability. The stories of two mothers and their disabled children are told using the concept of thresholds to examine their encounters with (the difference of) their children. The essay concludes with implications for professional practice. KEYWORDS Threshold; Disability; Normalization; Encounter; Movement
\end{abstract}

\section{INTRODUCTION}

We are inspired by Jonathan Wyatt's challenge to situate our research in the space of the threshold, indeed in "the discomfort-the terror-of the threshold." In his exploration of and experimentation with thresholds, Wyatt writes:

I don't know what to make of thresholds, and I'm not sure whether I like them, but my intuition, my gut, tells me it's where our research needs to be. I want to push thresholds. . . towards a place-a multiplicity of spaces and times-where categories (this and that, here and there) become indistinct, where we position ourselves and our inquiries as always in thresholds, forever liminal, forever refusing "here" or "there," seeking out the pauses, not the notes, in the song; the pauses as notes.

In such thresholds our research can be at its most critical, where we take nothing for granted, where everything is at stake. It means conducting inquiries as if we do not know where they will take us. As if there were no more time. $^{2}$

In what follows we will explore two mothers' stories of struggle and the difficulties they encounter(ed) in crossing the multiple thresholds they face(d) as they each have found ways to live with a child deemed, in normalizing majoritarian discourses and practices, to be not "fully" human. In taking up Wyatt's challenge,

Departures in Critical Qualitative Research, Vol. 4, Number 4, pp. 83-98. ISSN 2333-9489, electronic ISSN 2333-9497. (C) 2015 by the Regents of the University of California. All rights reserved. Request permission to photocopy or reproduce article content at the University of California Press's Reprints and Permissions web page, http://www.ucpress.edu/journals.php?p=reprints. DOI: 10.1525/dcqr.2015.4.4.83. 
we focus in particular on those thresholds where the abled/disabled binary is challenged and we situate our work in the often unspeakable "pause," between seeing the child with a disability as monstrous and embracing that child in all his or her humanity.

\section{CHILDREN WITH DISABILITIES AND THEIR FAMILIES: THE INFLUENCE OF DISABILITY STUDIES}

In this essay we take the concept and practice of thresholds into the field of disability studies, a field that is moving beyond the disability-as-deficit notion, ${ }^{3}$ wherein disability is a characteristic that is intrinsic to individuals, toward disability as a phenomenon, a construct, that finds its meaning in sociocultural spaces. ${ }^{4}$ As such, disability studies is characterized by multiple thresholds; the pause between each movement is a space of emotional and intellectual challenge. We can open up space to look for potentialities for conceptualizing disability as not (always) a lack, but an opportunity to revise notions of normality, independence, and autonomy. ${ }^{5}$ Disability studies' emerging focus is a critical and interdisciplinary examination of Susan Gabel's "dynamic interplay between disability and various aspects of culture and society." It generates encounters between "critical inquiry and political advocacy by utilizing scholarly approaches from the humanities, humanistic/post humanistic social sciences and the arts." ${ }^{\text {" Disability }}$ studies invites us to become careful and active listeners to what people with disabilities want and how they want to participate. It makes us think about ways we can/should support people with disabilities to enhance their participation and opportunities to participate. Inclusion and participation are essential to human dignity and to bring about a genuine equalization of opportunities. Disability studies recognizes the important roles family members play in the lives of many persons with disabilities. Scholarship in this area includes research into the views and experiences of family members. It is a living engagement; it applies to resources of our creative imagination in an attempt that is as much to disclose something about ourselves as it is to disclose something about the families. And in those encounters, disability studies seeks ways of being open to the not-yetknown, of learning from them-opening up new possibilities, crossing unanticipated thresholds, resisting normalization, and always being open to renewal. ${ }^{8}$

\section{THE TROUBLE WITH NORMALIZATION}

The processes of normalization causes trouble for those working with children categorized as disabled. Normalization works on us and through us in ways that 
are often invisible, as Judith Butler points out.' ${ }^{9}$ That invisibility is integral to the illusion of individual autonomy and freedom, an illusion that has been intensified through the dominant neoliberal discourses that have prevailed over the past three decades. ${ }^{\text {IO }}$ At the same time, Butler argues, the norms create a frame that is necessary if embodiment is to make sense:

if we consider that human bodies are not experienced without recourse to some ideality, some frame for experience itself, and that this is as true for the experience of one's own body as it is for experiencing another, and if we accept that that ideality and frame are socially articulated, we can see how it is that embodiment is not thinkable without a relation to a norm, or a set of norms. ${ }^{\text {II }}$

In taking up those norms as our own, those of us positioned as "normal" shape ourselves, and each other, in ways that our normativity is unmarked, unremarkable. Without necessarily paying this process much conscious attention, we come to regard those who lie outside the normative boundaries as "monstrous." ${ }^{2}$ This process of dividing off the disabled (them) from the normative and normalized (us) is one that generally happens without conscious intent.

A norm is a pattern regarded as typical, as the way things happen, or are said to be. The norm comes to be what is expected, and the expected slides quickly toward moral judgment, where is has turned into ought. The normative becomes the socially approved and mandated way of being. "The norm only persists as a norm to the extent that it is acted out in social practice and reidealized and reinstituted in and through the daily social rituals of bodily life."13 ${ }^{13}$ This move from normativity to moralism is not accidental. Normalization works in such a way that the horror is also internalized, at least in part, by the one who is abjected.
Sunaura Taylor, a disabled rights activist talks about her discomfort using her mouth to pick up her coffee cup. In a conversation with Judith Butler, Butler asks her if she feels free to move in all the ways she wants to move, and Taylor talks of having to pluck up her courage, in the pause before going into the coffee shop, where she must either ask for her cup to be carried for her, or else upset everyone by carrying it with her mouth: "I can go into a coffee shop and actually pick up the cup with my mouth and carry it to my table, but then that becomes almost more difficult because of the-just the normalizing standards of our movement, and of the discomfort that 
However discomfiting, and however much thresholds and the confrontation with norms fill us with terror, such as Taylor's entry into coffee shop, they are also openings that may hold possibilities and hope in them. causes when I do things with body parts that aren't necessarily what we assume they're for. That seems to be even more hard for people to deal with." ${ }^{14}$ There is a complex dance in the pronouns here. It is I who goes into the coffee shop, and my mouth and my table, but it is our normalizing standards and we who assume that bodies should only be used in the usual ways.

Taylor must cross the threshold into the coffee shop, she must cross again and again the threshold from her own internalized abjection to one who is courageous enough to break with the force of the normative gaze: "If my doing is dependent on what is done to me or, rather, the ways in which I am done by norms, then the possibility of my persistence as an "I" depends upon my being able to do something with what is done with me."15

The thought of the possible is deeply significant in the formation of viable lives, but for some, it is impossible to imagine what a possible life might be outside the normative: "The thought of a possible life is only an indulgence for those who already know themselves to be possible. For those who are still looking to become possible, possibility is a necessity." ${ }^{16}$ In what follows we explore the pause in that space where nothing seems possible, and the movements across thresholds, toward possible lives.

\section{THE UNSPEAKABLE NATURE OF MONSTROSITY}

The abject horror that may be experienced when first encountering the monstrous is difficult to write about, or to speak about. There are multiple, diffractive forces at play in generating that silence.

First, the normative force of discourse does not work on us and through us as a conscious choice; rather, in desiring recognition (without which we cannot survive) we take up social norms as if they were our own. As Butler asserts: 
Our very sense of personhood is linked to the desire for recognition, and that desire places us outside ourselves, in a realm of social norms that we do not fully choose, but that provide the horizon and the resource for any sense of choice that we may have. ${ }^{17}$

Second, the slippage from the normative is to the moralistic ought, when combined with what Butler refers to as the disavowal of dependence, ${ }^{18}$ means that one's abjection of the other to form one's own borders is not easily accessible to conscious inspection. Each one of us, through these processes, denies our own monstrosity in order to accomplish ourselves as recognizably human. The shock of being face to face with someone else who has or does what has been denied in oneself can be quite extreme. ${ }^{19}$ At the same time, there are contradictory moralisms at play: the disabled should be included in society and they should respond by becoming normal. Third, intertwined with the psychic life of abjection is the dominance of neoliberal discourses that shift responsibility for humanity's well-being away from the social and toward the individual - the individual disabled person, and their individual parents, become responsible for any failure to be and to become normal. Integral to the parents' accomplishing of their own ongoing normality is their acceptance of responsibility for the care of their child. At the same time the work of professionals who support those parents and their children has become increasingly prescriptive, often required by governmental agencies to provide pre-specified pathways toward autonomy and normativity. Fourth, the rapid development in medical and associated technologies means that a whole technological apparatus is poised to take control of that care, to shape how it can and should be done immediately. It assumes the language of correction, adaptation, rehabilitation, treatment, and normalization:

One has to submit to labels and names, to incursions, to invasions; one has to be gauged against measures of normalcy; and one has to pass the test.

Sometimes what this means is that one needs to become very savvy about these standards, and know how to present oneself in such a way that one comes across as a plausible candidate. ${ }^{20}$

This complex, multi-directional silence forms a void around which a great deal of work with the people with a disability circulates, making the pathway to embracing multiplicity a complex dance around that which cannot be spoken. In disability studies " $[\mathrm{t}]$ here is not just a single threshold but multiple thresholds, all simultaneously in play, baubles I am lunging to catch as they tumble from the falling Christmas tree." ${ }^{\text {2I }}$ 


\section{STANDING AT THE THRESHOLD: MARY'S STORY}

When Robert Hoge was born, the nurses did not show him to Mary, though they did tell her he was severely deformed. In the following days they began a program of gentle persuasion, urging her to cross the threshold of the nursery and look at her child. But thresholds can be very frightening with their unknown possibilities. First, they said, she should agree to see the child, and then, when she was ready, she should take him home. She resisted the push toward her child; yet in her resistance there lay a deep ambivalence. We hesitate on the threshold, not knowing where it might take us: that pause on the threshold, where all that once was certain is no longer so, can be both excruciating and necessary. No matter how painful, it is a pause that cannot be rushed. The pause itself is already part of the song that is yet to be sung.

"Perhaps it's how thresholds evoke indecision and hesitation. Or their suggestion of not knowing. Of nothing being settled. Of being neither one thing nor the other, neither here nor there."22
23 July 1972

It was a long, difficult labour for a fifth baby and I was born at 12.35 p.m. Had Mary then chosen to ask, "Is it a boy or a girl?" she may have been able to bask a little longer in that moment of perfection when a baby is born. Instead, maternal intuition made her ask, "Is my baby okay?"

"No, Mrs. Hoge," the doctor said, "He is not okay. He has a lump on his head and something wrong with his leg.". . .

Mary assumed my life was at risk and asked that I be baptised straight away. . . . Later that day, Mary found out the priest administered last rites immediately after baptizing me.

Mary didn't see me before I was taken and put into intensive care. But Vince had visited me. . . . he described me to her, and together they cried.

"Perhaps he'll die," Mary said.

It's impossible to know all the feelings going through my parents' minds at that time. Grief, bitterness, sorrow, horror and despair, for sure. . . .

So there I was. What should have been a wonderful birthday present [for Mary] was instead a little baby boy who was monstrously deformed and surely impossible to love. . . .

In those first few days Mary was asked again and again: Do you want to see your baby? Each time her answer was the same: No.

"I wished he would go away or die or something, I just wanted to be finished with it all. I told the hospital staff I didn't want my baby. I wouldn't under any circumstances take it home. I wouldn't even go and look at the baby.". . . . True to her word, she refused to see $\mathrm{me}^{23}$ 
Thresholds are just so liminal. ... we are always in between, always at or in a threshold, even when we think we have "arrived." Even when we are here, we are on the way there; on the way is already there. ${ }^{24}$

Mary paused in that liminal space in between the unspeakable-unthinkable-unseeable monstrosity of her child, and the act of claiming the child as her own, as a member of her family - to be embraced and loved.

She was befriended by a young doctor who came to talk to her each day-not about the baby, or her refusal, but about anything else Mary wanted to talk about. After some days had passed the doctor sensed a change in Mary and she asked her whether she was "ready to face the horror of seeing me in the flesh." 25

Two weeks after the birth of her baby, it occurred to Mary that her decision not to care for her son had been made at least in part to protect his siblings. She and her husband gathered them around the breakfast table, and invited them to make a collective decision.
Before she'd thought it through, she was there, standing over my cot. My mother looked down on me for the first time and saw the large tumour that had robbed her of a baby's beauty. She saw my too-widely spread eyes and my splayed nostrils. She saw my deformed legs and bent toes. Dr. Keating held Mary while she cried.

Mary looked again.

And she made up her mind that she did not care about her son.

"I didn't feel anything for this baby," she wrote. "I had shut off completely. I had made up my mind I was not taking him home. One nun kept telling me he was my responsibility and that I had to take him home. The more she told me this, the more determined I became that I wouldn't."

The choice was stark: either Mary took me home and battled with the day-to-day dramas associated with having a disabled and severely deformed baby, or she denied me, left me to be institutionalised behind $a$ wall somewhere and dealt with the guilt which would, hopefully, diminish over time. ${ }^{26}$

Finally, Vince and Mary agreed they should explain to my brothers and sisters exactly what was wrong with me and give everyone a chance to have their say. . . .

They explained the situation, describing what I looked like and what was wrong with my legs. They talked for a long time and when 
As it turned out, this was a threshold that could be crossed collectively; mother, father, and four siblings around the breakfast table could decide together to bring the "monster" home to their family. The first of many thresholds was crossed together, full of terror at the unknown shape of the life on which they were embarking, and also intense joy at the bringing home of a new baby into the family.

As Terry Galloway says: "It is thrilling to open a door that seemed nailed shut, to cross that threshold into the buzzing confusion of the world-and realize that I can listen to it now, play with what it is telling me and learn."27 There is another note after a pause. . they finished the whole family was crying. Then came the big question. My parents asked my siblings whether they thought they should bring me home.

Catherine-the youngest of the fourremembers Mary pointing at them one by one, and asking: "And you. What do you think? Should we bring him home?" In turn, each of them said yes: bring our brother home. ${ }^{28}$

\section{THE AMBIGUITY OF THE THRESHOLD: GREET'S STORY}

The movement across this particular threshold (and all the others that are yet to come) is complex, and yet parents are expected to move across it quickly, taking advice from professionals about the nature of the child's disability, how it is to be managed and the possible, future prospects.

It is not a crossing that can be managed with reason alone, nor by following a prescribed program of what should be done, not least because of the horror that largely remains unspeakable. Butler reminds us:

The questioning of taken-for-granted conditions becomes possible on occasion; but one cannot get there through a thought experiment, an epoché, an act of will. One gets there, as it were, through suffering the dehiscence, the breakup, of the ground itself. ${ }^{29}$

Parents experience an immense emotional contradiction between sorrow at what cannot be anticipated any longer-life with a beautiful, normal, happy child—and desire to embrace the child they did not anticipate—they do not know how to care for or love.

Henri Bergson analyzes the two contrary movements in which we are all continually caught up. The first is the line of descent-made up of repetitions of the already known, a space of comfort and predictability. The second is the 
line of ascent-the space of movement, of the threshold, where everything is open to change:

The universe endures. The more we study the nature of time, the more we shall comprehend that duration means invention, the creation of forms, the continual elaboration of the absolutely new.... [I]n the universe itself two opposite movements are to be distinguished .... The first only unwinds a roll ready prepared. In principle, it might be accomplished almost instantaneously, like releasing a spring. But the ascending movement, which corresponds to an inner work of ripening or creating, endures essentially, and imposes its rhythm on the first, which is inseparable from it. ${ }^{30}$

These two movements depend on each other. Yet what any person faces standing at this particular threshold is the fact that the first, the continuing repetition of the predictable world, is no longer possible. Letting go of safe ground can be compared to skydiving:

Skydiving involves a series of thresholds that are also points of no return. The first is the moment of letting go, surrendering to the jump or fall. This moment is one of both intense confusion and clarity. When you step out of the door of an aircraft, you face winds up to roo miles an hour. Using all of your strength to fight this wind, your muscles are tight as you cling to the outside of the aircraft. Then you let go. Fear is replaced with exhilaration. Embodiment is total. The past and the future seem to have no consequence. There is only present, action, and reaction. ${ }^{31}$

Greet Van Mossevelde, the mother of Heleen, whose story we move to now, first wrote her story in collaboration with the Elisabeth De Schauwer for a joint presentation at a conference. ${ }^{32}$

With the birth of a small child everyone has to, even if everything is okay, share that small human being with others, people who are not your family or people you do not feel any connection with. Nurses, doctors. . . steer you in how to handle the situation with that little person. We were confronted at birth with the fact that there was something wrong with our little girl. She was too small. It seems only a detail, but the consequences were and are huge. Heleen was two weeks in neonatology
The liminal space of those first two weeks was not somewhere anyone would choose to be. Greet and her husband, together, were not in a position to enjoy the birth of their second daughter. They were caught up in an event that was unlike anything they already knew. They were on the threshold of a major transformation and it felt like the skydiver's leap from the solid surface of the plane. They were in a place characterized by intense confusion and crystal clarity, filled with 
and they did several tests, without giving us much explanation. She was in the hands of 3 pediatricians in 6 days. Our own doctor left a message, via the nurses, that Heleen could go home after a week. The day after, the nurses told us that the pediatrician, in the interim, did not want to take that responsibility because her colleague had not talked to her about Heleen's discharge. I do not need to explain how shattered we felt at that stage. Fear, anger, and a lot of sadness were following each other very quickly. Now we felt the victim of two doctors.

After daily pressure and in the end, begging, we finally got an appointment with our doctor. He scared me that Heleen was not eating enough. I wanted a lot of extra information about what was going on with our little girl and I asked $a$ lot of questions. Apparently the doctor thought I was difficult and he said to me: "Leave all the thinking and brooding up to us." I stood there astonished, with my mouth shut. As a mother of a child with problems I was not permitted to worry? Thinking was also not allowed, as far as people start from the premise that a parent of a child with special needs is able to think. . terror. Through a series of such thresholds they would eventually discover the ways to pick up their lives as parents, and as a family, with a child with a disability. They were literally fighting for their own survival, a fight in which all they could focus on were the problems they faced with Heleen, grasping every small straw they could to build their new life; and, at the same time, they struggled to find ways to connect with Heleen, to relate to her as their daughter, as human, and to insist to the world that she is not just a disabled monster, but also a daughter like anyone else's daughter.

Greet and Piet needed to become "mother/ father," "activist," "care giver," "consultant," "researcher," and "lawyer" all at once and negotiate these different identities in encounters with others even while being told they did not have to think about professional care for Heleen. ${ }^{33}$ Everything and everyone surrounding Heleen destroyed-in a flashall that they thought they knew. How could they become recognizable in this new situation? No longer able to be what they were, they stood at a threshold where they themselves became the conduit of change: "It involves achieving some recognizable human form that also resonates meaningfully with others and our circumstances. We become a threshold ourselves-a conduit of possibilities." ${ }^{34}$

And so the normalizing discourse is turned against the parents, "a discourse that is not yours, a discourse that effaces you in the act of representing you, a discourse that denies 
have syndrome $X, Y$, or $Z$, we had the feeling she would no longer be Heleen. She would lose the name we had chosen for her, her beautiful name, we picked so carefully. There was a lot of genetic research. There was no clue of what we were looking for. Syndrome of Rett, Angelman Syndrome, Catch 22. . . As soon as a doctor named something, we began to look ourselves. We wanted to do our own research, eliminate it or be prepared. Not knowing what it is, but constantly being aware of what it could be, it drove us crazy. We started to behave like what they thought we were. The insecurity was killing us.

The label of autism fell really quickly. Through my job in child rehabilitation, I had become very suspicious of the label. We were terribly worried that a label would diminish her chances, Heleen would be reduced to a label. The special child care facility was convinced. We were referred to a specialized center that would give a final judgment. I deliberately asked the child care center not to talk about their assumptions related to autism. The first thing we heard when we entered the hospital: "You know that the center thinks it's autism?" Our blood began to boil. . . . They had broken our trust. We could do nothing except start to offer counterevidence and look for other possible explanations for her behavior. They the language you might want to use to describe who you are, how you got here, and what you want from this life." 35 Parents, they discover, are themselves the problem if they think and ask too many questions. They want to recognize their child as normal and viable even while they see that possibility rapidly disappearing. They stand at a threshold, afraid, and wanting to take action-but they cannot yet see what action is possible. They will soon enough be caught up in battles in every domain of life. They plead to see and work with the capacities of their child; they engage in an ongoing struggle against the (unavoidable) positioning of their child, their parenthood, and their family life as "disabled," as "less worthy." Greet rails against the precipitous rush of the medical profession. And so she must pause in this moment as the song of Heleen is unfolded.

Greet describes being pulled forward into the diagnosis for therapeutic possibilities it might open up, for the chance it gives them all to mark time in the first of Bergson's movements, where repetition of the already known offers comfort and certainty. But it was no more than a small rest, for living with a child with a disability means dealing with continuous unpredictability. For Greet, the possibility of Bergson's second movement "the ascending movement, which corresponds to an inner work of ripening or creating ${ }^{\prime 36}$ is blocked by the positioning of the professionals, who find it difficult to listen to her, or to stay with her in the pause, before what they believe makes sense to her. 
listened to us and showed understanding. But all our arguments were pulled to pieces and we became the parents-who-could-notaccept-their-child-was-autistic. We kept on throwing ourselves in all kind of curves to recognize them in their expertise and also to be able to be heard and make some proposals for the support to which Heleen was entitled.

As a parent, you develop, luckily. We saw that a diagnosis of autism had some advantages to offer. It gave us information, explanations for behavior we did not understand. A diagnosis takes away the blame, it means that those around you can begin to show understanding. I noticed I now start to use it a lot more. Maybe because I am ready for it? Maybe the advantages suit me better now? It permits us in any case to give an excuse if Heleen's behavior gets "terribly difficult."
Encounters between a child with a disability and her family demand time and space for them to attune to each other-which in turn requires of each being open to being affected by the other. That openness is vital. Being stuck in what one knows already offers the other only a path of resistance, meaning no movement on either side is possible.

Opening up to what is possible takes time; it cannot follow orders or readymade prescriptions.

\section{IMPLICATIONS FOR PROFESSIONAL PRACTICE}

Understanding how normalization is at work on themselves and on the families they work with is vital for practitioners, however difficult a challenge that might be. In Deleuzian terms, challenging the processes of normalization is a matter of deterritorialization, which involves a move away from the center to the periphery, to the limits of what is deemed acceptable in majoritarian norms. ${ }^{37}$ "Deterritorialization has the potential to attack the rigid, striated-or territorialized—spaces. . replacing these with ones which are smooth and full of creative possibilities. ${ }^{38}$

The majoritarian discourse is afraid of such spaces. Unwilling to challenge its own authoritative knowledges, it lodges itself on Bergson's line of descent, endlessly repeating the already known. It generates and strengthens a specialized circuit for children categorized as disabled. Because of their special needs, they are seen as requiring "treatment," and they are morally obliged to compensate for their deficits before they can be deemed to be "ready" to participate in the "ordinary" world. 
Without a continual effort to understand these dynamics, the expertise of the parents is often misjudged and dismissed by those professionals caught in these lines of descent, where what is "true" cannot be subjected to critical scrutiny by non-experts. Parents who resist this closed reality are seen simply as not accepting reality. But reality, in Deleuzian terms, is not stable and fixed; it is not predictable. Gilles Deleuze offers a different possibility of breaking open the image of the individual as able to be fixed within normative structures where they are dependent on the repetitive re-citation of recognition and recognizability within already known categories. ${ }^{39}$

The reliance on categorization is, however, deeply embedded in disability studies. It is vital that the role of categorization in shaping what is possible is questioned continually. The dangers of the category work hand in hand with the freedoms and possibilities it opens up. The dangers lie in the binary thinking that positions persons with a disability as other to the norm, as other to human. The act of recognition, in Butler's terms, ${ }^{4 \circ}$ must keep open the tension between these two poles of danger and freedom, keeping it alive and productive. The productive tension is maintained when disabled children and adults are understood as being both abled and disabled, both different and the same-like Sunaura Taylor with her coffee cup. The binary must be worked so as to keep both sides open. In holding both sides open, by default, the category of human can be expanded to include those who are more often placed at the margins.

Through holding together the insights from both Deleuze and Butler, it is possible for professionals to imagine the people they work with-the children and their families - as engaged in a continual process of becoming in their encounters with each other and with the professionals who work with them. This demands different ways of looking at, working with, and listening to parents, requiring both a reflexive awareness of discourses at work on and through all of the participants, and a willingness not to be fooled by categories, even while mobilizing them. This in turn requires an immersion in each encounter-in which each is open to being affected by the other as they move with each other over the multitude of thresholds before them. "Thresholds in perception and thought ask us to attend to transformations in routes, routines, states, spaces, expectations, and the terms of interaction and engagement." ${ }^{4 \mathrm{I}}$ This involves an ongoing affective and relational openness to the questions, hopes, desires, and fears of parents.

What we are suggesting here is that in every encounter with every child and every family, professionals open themselves, in a positive way, to being vulnerable to what they do not know yet. This involves, like the young doctor who 
befriended Robert Hoge's mother, a willingness to stand by the parents at every turn, at every pause, on the brink of what looks like a precipice. This involves a capacity to recognize the enormous effort that each child and their families are putting in, and it requires a non-judgmental ethics. ${ }^{42}$ To work with people standing at this threshold requires a "willingness to be unsure, to be wrong, to try things and to make mistakes. Such willingness is necessary to preserve our vitally important capacity to be surprised." ${ }^{23}$ It asks not for readymade answers but for a mapping of the ways in which we are connected in the world in different places and times, and to comprehend how these connections are vital to the construction of humanity itself.

\section{AND SO...}

We began this essay with no clear idea where it would take us. With help from the authors in the Spring 2014 issue of Departures in Critical Qualitative Research, and also from Butler and Deleuze, we have made our way toward an understanding of the vital work done by parents as they pause on the threshold of the unknown, like the skydiver, not knowing how they might create a viable life with and for their abled/disabled child(ren). We have examined the powerful force of normalization that works outside consciousness to normalize some and place those who are differently embodied on the borders outside humanity; we have looked at the ambivalent work of categories as they seek to delimit and dictate what the diagnosed child is, while also providing a safe and predictable place for the work to begin. We have shown how willingness to pause on the threshold with the parent, no matter how long that pause might take, makes possible a respectful encounter in which each is open to being affected by the other. We have argued that the task is not so much to fix reality in place with diagnostic categories and prescriptions for practice, but to see that life is an ongoing series of encounters through which change takes place. Each of us is a work in progress, each of us is emergent in the possibilities opened up in encounters with others. Our openness to what we do not yet know is, as Bergson argues, what enables us, collectively, to endure, to find the ways in which we might creatively evolve with each other, expanding what it is possible to think and to do.

\footnotetext{
Elisabeth De Schauwer is Postdoctoral Assistant in the Department of Special Needs Education at Ghent University. Correspondence to: Elisabeth De Schauwer, Department of Special Needs Education, Faculty of Psychology and Educational Sciences, Ghent University, Henri Dunantlaan 2, B-9000 Gent, Belgium. Email: elisabeth.deschauwer@ugent.be.

BRonwyn DAvies is an independent scholar based in Sydney, Australia. She is also a Professorial Fellow at the University of Melbourne. Website: bronwyndavies.com.au.
} 


\section{NOTES}

I. Jonathan Wyatt, "Always in Thresholds," Departures in Critical Qualitative Research 3, no. I (2014): 8 .

2. Ibid., 16 original emphasis.

3. Susan Gabel, Disability Studies in Education: Readings in Theory and Method. (New York: Peter Lang, 2005).

4. Steven Taylor, "Introduction," in Disability Studies: Information and Resources, ed. Steven Taylor, Bonnie Shoultz, and Pamela Walker (Syracuse, NY: Centre on Human Policy, School of Education, 2003), I-5, accessed June 2014, http://thechp.syr.edu/wpcontent/uploads/2013/10/Disability_Studies_2003_current.pdf.

5. Daniel Goodley and Katherine Runswick-Cole, "Becoming Dishuman: Thinking about the Human through Dis/ability," Discourse: Studies in the Cultural Politics of Education (2014): DOI: 10.1080/01596306.2014.930021.

6. Gabel, Disability Studies in Education, I.

7. Ibid.

8. Lennard J. Davis, Enforcing Normalcy: Disability, Deafness and the Body (New York: Verso, 1995).

9. Judith Butler, The Psychic Life of Power: Theories in Subjection (Stanford, CA: Stanford University Press, 1997).

ı. Bronwyn Davies, Elisabeth De Schauwer, Lien Claes, Katrien De Munck, Inge Van de Putte, and Meggie Verstichele, "Recognition and Difference: A Collective Biography," International Journal of Qualitative Studies in Education 26, no. 6 (2013): 684.

II. Judith Butler, Undoing Gender (New York: Routledge, 2004), Io.

I2. Margrit Shildrick, Embodying the Monster: Encounters with the Vulnerable Self (Thousand Oaks, CA: Sage, 2002).

I3. Butler, Undoing Gender, 48.

I4. "Examined Life-Judith Butler \& Sunaura Taylor 720p.avi," YouTube, 6 October 20I0, accessed io September 20I2, http://www.youtube.com/watch?v=koHZaPkF6qE emphasis added.

15. Butler, The Psychic Life of Power, 3 emphases added.

16. Butler, Undoing Gender, 3 I.

17. Ibid., 33 .

18. Butler, The Psychic Life of Power.

19. Shildrick, Embodying the Monster.

20. Butler, Undoing Gender, 9 I.

2I. Wyatt, "Always in Thresholds," II.

22. Ibid.

23. Robert Hoge, Ugly: My Memoir (Sydney: Hachette, 2013), 3-6 original emphases.

24. Wyatt, "Always in Thresholds," II-I2.

25. Hoge, Ugly, 7.

26. Ibid., 7-8.

27. Terry Galloway, "Strike Up the Band," Departures in Critical Qualitative Research 3, no. I (2OI4): 22.

28. Hoge, Ugly, iा. 
29. Butler, Undoing Gender, 107-108 original emphasis.

30. Henri Bergson, Creative Evolution, trans. Arthur Mitchell (Mineola, NY: Dover, I998), II-I2 original emphases.

31. Noelle Mason, "Decision Altitude: Incident Report," Departures in Critical Qualitative research 3, no. I (2014): 44.

32. Greet Van Mossevelde and Elisabeth De Schauwer, "Process of Collaborative Working between Parents and Professionals" (presentation at the Symposium on Intensive Support Teams in Flanders, Ghent, 3 December 2010).

33. Geert Van Hove, Elisabeth De Schauwer, Kathleen Mortier, Sigrid Bosteels, Greetje Desnerck, and Jos Van Loon, "Working with Mothers and Fathers of Children with Disabilities: Metaphors Used by Parents in a Continuing Dialogue," European Early Childhood Education Research Journal 17, no. 2 (2009): 187-201.

34. William K. Rawlins, "Brimming Moments: Rhythm, Will, Readiness, and Grace," Departures in Critical Qualitative Inquiry 3, no. I (2014): 85.

35. Butler, Undoing Gender, 90.

36. Bergson, Creative Evolution, II.

37. Gilles Deleuze and Félix Guattari, A Thousand Plateaus: Capitalism and Schizophenia, trans. Brian Massumi (London: Continuum, 2004), 307.

38. Julie Allan, Rethinking Inclusive Education. The Philosophers of Difference in Practice (Dordrecht, Netherlands: Springer, 2008), 63.

39. Gilles Deleuze, Difference and Repetition, trans. Paul Patton (New York: Columbia University Press, 2004).

40. Butler, Undoing Gender, 133 .

4I. Stacy Holman Jones, “An Opening to Dream," Departures in Critical Qualitative Research 3, no. I (2014): 2.

42. Jonathan Wyatt and Bronwyn Davies, "Ethics," in Deleuze \& Collaborative Writing: An Immanent Plane of Composition, ed. Jonathan Wyatt, Ken Gale, Susanne Gannon, and Bronwyn Davies (New York: Peter Lang, 201I), I05-30.

43. Rawlins, "Brimming Moments," 83. 